\title{
Early intervention using high-precision radiotherapy preserved visual function for five consecutive patients with optic nerve sheath meningioma
}

\author{
Toshihiko Inoue ${ }^{1}$ D $\cdot$ Osamu Mimura ${ }^{2} \cdot$ Norihisa Masai $^{3} \cdot$ Atuyuki Ohashi $^{1} \cdot$ Koji Ikenaga $^{1} \cdot$ Yoshishige Okuno $^{1}$. \\ Iku Nishiguchi ${ }^{1} \cdot{\text { Ryoongjin } \mathrm{Oh}^{3}}^{3}$
}

Received: 4 March 2018 / Accepted: 24 April 2018 / Published online: 30 April 2018

(C) The Author(s) 2018

\begin{abstract}
Background There has been a paradigm shift in the treatment for optic nerve sheath meningioma (ONSM) from surgery to fractionated stereotactic radiotherapy (FSRT) in other countries. However, FSRT has seldom been performed in Japan. The purpose of this retrospective study is to reconfirm the effectiveness of early intervention with precision radiotherapy for ONSM reported in our previous study.

Methods Five consecutive patients with ONSM were retrospectively analyzed. All patients underwent intensity-modulated radiotherapy (IMRT) or FSRT. They received the early interventions between 1.5 and 7 months after deterioration of the disease. The median dose was 52.8 Gy (range 46.0-59.4 Gy) and the median number of fractions was 25 (range 22-33).

Results All patients experienced reestablishment of vision at the median follow-up time of 36 months (range 18-54 months). Four of them noted early improvement of visual deficits during the treatment course (range 2-4 weeks) and the remaining patient improved 3 weeks after completion of IMRT. The median tumor reduction was 53\% (range 39-75\%). One patient with diabetes mellitus developed retinal bleeding as a result of radiation retinopathy 16 months after IMRT, although the doses were acceptable. The remaining 4 patients have no late toxicity at the follow-up time of 31-54 months.

Conclusions A paradigm shift is necessary from surgery to early intervention using precision radiotherapy for the treatment of ONSM in Japan.
\end{abstract}

Keywords Optic nerve sheath meningioma $\cdot$ IMRT $\cdot$ FSRT $\cdot$ Early intervention $\cdot$ Visual function

\section{Introduction}

There has been a paradigm shift in the treatment of ONSM from surgery to fractionated stereotactic radiotherapy (FSRT) during the last 2 decades in other countries, such as USA and Germany $[1,2]$. Optic nerve sheath meningioma (ONSM) is rare tumor and could potentially be treated by a neurosurgeon, plastic surgeon, or ophthalmological surgeon in Japan. In addition, most Japanese surgeons use surgical

Toshihiko Inoue

toinoue@r6.ucom.ne.jp

1 Ashiya Radiotherapy Clinic Nozomi, 3-84 Yoko-cho, Ashiya 659-0034, Japan

2 Department of Neuro-ophthalmological Therapeutics, Hyogo College of Medicine, Nishinomiya, Japan

3 Miyakojima IGRT Clinic, Osaka, Japan interventions at an advanced stage of visual loss, i.e., blindness. Accordingly, FSRT has seldom been performed in our country. In a previous case report, we described early intervention with FSRT in a patient with ONSM that resulted in a rapid and complete improvement of visual impairment [3]. As 4 patients, who underwent intensity-modulated radiotherapy (IMRT) in another clinic, have since been added into the study, 5 consecutive patients with ONSM were reviewed and retrospectively analyzed.

\section{Patients and treatment methods \\ Patients}

Between September 2013 and May 2015, we accrued 5 consecutive patients with ONSM who underwent IMRT or FSRT for analysis in this study. All patients were diagnosed 
with ONSM by an ophthalmologist (OM). They were examined by one of the authors (TI), who has consecutively belonged to both clinics, i.e., Miyakojima IGRT Clinic and Ashiya Radiotherapy Clinic Nozomi, to make a treatment decision about IMRT or FSRT. We obtained written informed consent from the patient for publication of the case details and any accompanying images. The plenary meeting of this clinic approved the study design, which included a chart review [3]. With regard to the additional 4 patients treated with IMRT in another clinic, the study protocol with opt-out consent was approved by the Institutional Review Board (IRB). Informed consent was obtained from all 4 patients.

Patients and tumor characteristics are shown in Table 1. The median age was 46 years (range: $34-61$ years). There were 2 men and 3 women. One of the patients had intercurrent diabetes mellitus. Three patients had lesions in their left eye and 2 had lesions in their right eye. Four patients had tumors located in the intraorbital region. The remaining patient had a tumor in the intracanalicular region. Concerning the shape of tumors, there were fusiform and tubular tumor types in 2 patients each, and a global tumor in the remaining patient [4]. The median volume of the tumor was $0.44 \mathrm{~cm}^{3}$ (range $0.20-0.90 \mathrm{~cm}^{3}$ ). At the time of treatment initiation, the median corrected visual acuity (VA) in the involved eye was 0.29 (log MAR visual acuity: 0.544 ) (range 0-1.7). We set MAR to the minimum angle of resolution. The median value of the central critical flicker-fusion frequency (CFF), which represents functional impairment of the optic nerve before the significant depression of VA, was 23.5 (range N/V-41.5). With regard to the visual field (VF), 3 patients suffered from quadrantanopsia and two had centrocaecal scotoma. The mean deviation (MD) of sensitivity depression was -16.18 (range -1.30 to N/A) in the involved eye with Humphrey automated perimetry (HAP).

\section{Methods}

Treatment characteristics are summarized in Table 2. The median time from disease onset and rapid deterioration to treatment initiation was 19 and 3 months (range 11-41 and 1.5-7 months), respectively. Four patients underwent IMRT and the remaining patients received FSRT. The median prescription dose was 52.8 Gy (range 46.0-59.4 Gy). The median number of fractions was 25 (range 22-33). The median overall treatment days were 35 days (range 31-45 days). Median numbers of beams was 7 (range 5-9). All patients were treated with a $6 \mathrm{MV}$ X-ray Novalis unit ${ }^{\mathrm{TM}}$ (BrainLAB AG, Munich, Germany).

In general, as the size of the target volume increases, the risk of damage to the organ at risk (OAR) such as the optic nerve, chiasm, and retina increases. Therefore, for four patients treated with IMRT, we tried to decrease the planning target volume (PTV) as small as possible. The gross tumor volume (GTV) was determined with CT-MRI fusion image to improve the accuracy of delineation of the

Table 1 Patient and tumor characteristics

\begin{tabular}{|c|c|c|c|c|c|}
\hline \#Patient & $\# 1$ & \#2 & \#3 & \#4 & $\# 5$ \\
\hline Age (years) & 35 & 57 & 46 & 61 & 41 \\
\hline Sex & Female & Female & Female & Male & Male \\
\hline Intercurrent disease & $(-)$ & $(-)$ & $(-)$ & Diabetes mellitus & $(-)$ \\
\hline \multicolumn{6}{|l|}{ Tumor } \\
\hline Laterality & Left & Right & Left & Right & Left \\
\hline Location & Intraorbital & Intraorbital & Intracanalicular & Intraorbital & Intraorbital \\
\hline Shape & Fusiform & Fusiform & Tubular & Tubular & Globular \\
\hline Size $(\mathrm{mm})$ & $23 \times 9 \times 10$ & $13 \times 5 \times 6$ & $16 \times 10 \times 8$ & $18 \times 9 \times 8$ & $9 \times 6 \times 8$ \\
\hline Volume $\left(\mathrm{cm}^{3}\right)$ & 0.87 & 0.20 & 0.44 & 0.90 & 0.30 \\
\hline \multicolumn{6}{|c|}{ Corrected VA in the affected eye } \\
\hline Log MAR (decimal) & $0.3(0.5)$ & $0.22(0.6)$ & $0.5(0.3)$ & $0(1.0)$ & $1.7(0.02)$ \\
\hline \multicolumn{6}{|l|}{$\mathrm{CFF}$} \\
\hline Right $(\mathrm{Hz})$ & $43-44(43.5)$ & 30 & $53 / 42(47.5)$ & $41 / 42(41.5)$ & $41 / 42(41.8)$ \\
\hline Left $(\mathrm{Hz})$ & $23-24(23.5)$ & 40 & $13 / 10(11.5)$ & $38 / 41(39.5)$ & N/A \\
\hline Visual field & Quadrantanopsia & Quadrantanopsia & Centrocecal scotoma & Quadrantanopsia & Centrocecal scotoma \\
\hline \multicolumn{6}{|l|}{ HAP } \\
\hline Right MD (dB) & -0.59 & $-16.18 p<0.5 \%$ & $-1.36 p<10 \%$ & -1.30 & N/A \\
\hline Left MD (dB) & -8.9 & -0.12 & $-24.35 p<0.5 \%$ & +2.00 & N/A \\
\hline
\end{tabular}

$V A$ visual acuity, $\log M A R$ logarithm of minimum angle of resolution, $C F F$ critical flicker-fusion frequency, N/A not available, $H A P$ Humphrey automated perimetry, $M D$ mean deviation of sensitivity depression with HAP 
Table 2 Treatment characteristics

\begin{tabular}{|c|c|c|c|c|c|}
\hline \#Patient & $\# 1$ & $\# 2$ & $\# 3$ & $\# 4$ & $\# 5$ \\
\hline Onset to Trx (months) & 41 & 19 & 19 & 20 & 11 \\
\hline Deterioration to $\operatorname{Trx}$ (months) & 7 & 3 & 2 & 4 & 1.5 \\
\hline Trx method & IMRT & IMRT & IMRT & IMRT & FSRT \\
\hline Prescription dose (Gy) & 59.4 & 54 & 52.8 & 46 & 50 \\
\hline \#Fractions & 33 & 30 & 22 & 23 & 25 \\
\hline Days & 45 & 43 & 33 & 31 & 35 \\
\hline \#Beams & 7 non-coplanar & 7 non-coplanar & 9 non-coplanar & 7 non-coplanar & 5 coplanar \\
\hline
\end{tabular}

$\operatorname{Tr} x$ treatment, IMRT intensity-modulated radiotherapy, FSRT fractionated stereotactic radiotherapy, NED no evidence of disease

GTV. We defined the GTV as the clinical target volume (CTV). In the parts with mobility accompanying eyeball movements, the internal margin (IM) of $1 \mathrm{~mm}$ was added to the CTV in every direction excluding anterior and was defined as internal target volume (ITV). In other parts, we defined the CTV as the ITV. The PTV was defined as the ITV plus the set-up margin (SM) of $2 \mathrm{~mm}$. Therefore, the GTV mean of $0.6 \mathrm{~cm}^{3}$ resulted in the PTV mean of $2.2 \mathrm{~cm}^{3}$. In dose constraints for OARs, we determined $D_{2 \%}$ and $D_{\text {mean }}$ of the optic nerve, chiasm, and retina as upper limits of biologically equivalent dose at 2 Gy per fraction $\left(\mathrm{EQD}_{2}\right)$ of $60 \mathrm{~Gy}$ and $45 \mathrm{~Gy}$, respectively. In the case of patient \#5 treated with FSRT, we defined GTV of $0.3 \mathrm{~cm}^{3}$ using CT and MRI, and the PTV was $1.7 \mathrm{~cm}^{3}$, which was based on a 3- $\mathrm{mm}$ margin added to the ITV [3]. Details of the treatment devices and methods were reported previously $[3,5,6]$.

\section{Results}

All patients had improved and re-established VA and VFs at the median follow-up time of 36 months (range 18-54 months). Four of the patients experienced improvement in their visual deficits during the treatment course (range 2-4 weeks). The remaining patient showed improvement 3 weeks after completion of IMRT (Table 3). Since the tumors showed slow regression after completion of IMRT or FSRT based on the benign nature of the disease, the median reduction of the tumor size was 53\% (range 39-75\%). One patient achieved a 53\% tumor reduction at 16 months; however, he was lost to follow-up 18 months after the completion of radiotherapy. The remaining 4 patients have not experienced any adverse events, and have returned to their normal lives.

The dose-volume histogram (DVH) parameters for the planning target volume (PTV), gross tumor volume (GTV), optic nerve, retina, disk, eyeball and chiasm of the 5 patients are listed in Table 4 . The median $D_{95 \%}$, i.e., minimum dose

\begin{tabular}{llllll}
\hline \#Patient & $\# 1$ & $\# 2$ & $\# 3$ & $\# 4$ & $\# 5$ \\
\hline $\begin{array}{l}\text { Early improvement of } \\
\text { Visual acuity (weeks)* }\end{array}$ & Yes (9) & Yes (4) & Yes (4) & Yes (2) & Yes (2) \\
$\begin{array}{l}\text { Visual field (weeks)* } \\
\text { Final reestablishment in involved eye (es) }\end{array}$ & Yes (4) & Yes (2) & Yes (2) & Yes (2) \\
Visual acuity (months)* & $(1.2)(51)$ & $(1.2)(43)$ & $(1.2)(34)$ & $(0.9)(18)$ & $(1.2)(27)$ \\
MD (dB) (months)* & $-0.32(51)$ & $-0.81(43)$ & $-3.54(34)$ & N/A (18) & $+0.61(27)$ \\
Tumor response & & & & & \\
Tumor size (mm) & $16 \times 8 \times 6$ & $11 \times 4 \times 5$ & $11 \times 8 \times 6$ & $16 \times 6 \times 6$ & $5 \times 3 \times 6$ \\
Tumor volume (cm $\left.{ }^{3}\right)$ & 0.47 & 0.12 & 0.11 & 0.42 & 0.08 \\
$\quad$ Tumor reduction (\%) (months)* & $46 \%(54)$ & $39 \%(46)$ & $75 \%(36)$ & $53 \%(18)^{\$}$ & $73 \%(27)$ \\
Status & NED & NED & NED & Retinal bleeding & NED \\
Follow-up (months)* & 54 & 46 & 36 & 18 & 34 \\
\hline
\end{tabular}

$N E D$ no evidence of disease, $M D$ mean deviation of sensitivity depression with Humphrey automated perimetry

*After the start of IMRT or FSRT

${ }^{\$}$ At the last examination, thereafter lost to follow-up 
Table 4 DVH parameters

\begin{tabular}{|c|c|c|c|c|c|}
\hline \#Patient (prescription dose) & \#1 (59.4 Gy) & \#2 (54 Gy) & \#3 (52.8 Gy) & \#4 (46 Gy) & \#5 (50 Gy) \\
\hline \multicolumn{6}{|l|}{ PTV } \\
\hline$D_{95 \%}$ & $58.9 \mathrm{~Gy}$ & $50.3 \mathrm{~Gy}$ & $45.8 \mathrm{~Gy}$ & $45.1 \mathrm{~Gy}$ & $47.9 \mathrm{~Gy}$ \\
\hline$V_{107 \%}$ & $0.1 \mathrm{~cm}^{3}$ & $0 \mathrm{~cm}^{3}$ & $0.3 \mathrm{~cm}^{3}$ & $0 \mathrm{~cm}^{3}$ & $0.6 \mathrm{~cm}^{3}$ \\
\hline$D_{98 \%}$ & $58.0 \mathrm{~Gy}$ & 45.6 Gy & 43.5 Gy & 44.7 Gy & $47.0 \mathrm{~Gy}$ \\
\hline$D_{50 \%}$ & $61.6 \mathrm{~Gy}$ & $54.4 \mathrm{~Gy}$ & $53.5 \mathrm{~Gy}$ & 46.9 Gy & $52.5 \mathrm{~Gy}$ \\
\hline$D_{2 \%}$ & $63.3 \mathrm{~Gy}$ & $56.1 \mathrm{~Gy}$ & $56.3 \mathrm{~Gy}$ & $47.8 \mathrm{~Gy}$ & $55.5 \mathrm{~Gy}$ \\
\hline \multicolumn{6}{|l|}{ GTV } \\
\hline$D_{98 \%}$ & $60.7 \mathrm{~Gy}$ & $54.5 \mathrm{~Gy}$ & 50.4 Gy & $46.7 \mathrm{~Gy}$ & $51.7 \mathrm{~Gy}$ \\
\hline$D_{50 \%}$ & $61.8 \mathrm{~Gy}$ & $55.2 \mathrm{~Gy}$ & $54.5 \mathrm{~Gy}$ & $47.3 \mathrm{~Gy}$ & $54.4 \mathrm{~Gy}$ \\
\hline$D_{2 \%}$ & $63.3 \mathrm{~Gy}$ & $56.0 \mathrm{~Gy}$ & 56.4 Gy & $47.8 \mathrm{~Gy}$ & $55.6 \mathrm{~Gy}$ \\
\hline \multicolumn{6}{|l|}{ Optic nerve } \\
\hline$D_{2 \%}$ & $63.2 \mathrm{~Gy}$ & $56.0 \mathrm{~Gy}$ & $55.0 \mathrm{~Gy}$ & $47.8 \mathrm{~Gy}$ & $54.0 \mathrm{~Gy}$ \\
\hline$D_{0.1 \mathrm{~cm}^{3}}$ & $62.5 \mathrm{~Gy}$ & $55.5 \mathrm{~Gy}$ & $40.1 \mathrm{~Gy}$ & 47.7 Gy & $52.2 \mathrm{~Gy}$ \\
\hline$D_{\text {mean }}$ & $52.3 \mathrm{~Gy}$ & $38.1 \mathrm{~Gy}$ & $12.6 \mathrm{~Gy}$ & $31.5 \mathrm{~Gy}$ & $25.8 \mathrm{~Gy}$ \\
\hline \multicolumn{6}{|l|}{ Retina } \\
\hline$D_{2 \%}$ & $19.5 \mathrm{~Gy}$ & 8.0 Gy & 0.9 Gy & $47.2 \mathrm{~Gy}$ & $1.6 \mathrm{~Gy}$ \\
\hline$D_{0.1 \mathrm{~cm}^{3}}$ & $16.3 \mathrm{~Gy}$ & 6.9 Gy & $0.6 \mathrm{~Gy}$ & $46.0 \mathrm{~Gy}$ & $1.2 \mathrm{~Gy}$ \\
\hline$D_{0.5 \mathrm{~cm}^{3}}$ & 4.0 Gy & $2.1 \mathrm{~Gy}$ & 0.4 Gy & $17.3 \mathrm{~Gy}$ & 0.7 Gy \\
\hline$D_{1 \mathrm{~cm}^{3}}$ & $1.1 \mathrm{~Gy}$ & $0.6 \mathrm{~Gy}$ & $0.3 \mathrm{~Gy}$ & $0.2 \mathrm{~Gy}$ & $0.3 \mathrm{~Gy}$ \\
\hline$D_{\text {mean }}$ & $2.8 \mathrm{~Gy}$ & $2.0 \mathrm{~Gy}$ & $0.3 \mathrm{~Gy}$ & $13.0 \mathrm{~Gy}$ & $0.8 \mathrm{~Gy}$ \\
\hline Disk (point dose) & 23.4 Gy & 8.0 Gy & $0.5 \mathrm{~Gy}$ & $47.2 \mathrm{~Gy}$ & $5.0 \mathrm{~Gy}$ \\
\hline \multicolumn{6}{|l|}{ Eyeball } \\
\hline$D_{2 \%}$ & $12.0 \mathrm{~Gy}$ & 6.7 Gy & 0.5 Gy & $45.0 \mathrm{~Gy}$ & $1.2 \mathrm{~Gy}$ \\
\hline$D_{1 \mathrm{~cm}^{3}}$ & 4.4 Gy & $2.1 \mathrm{~Gy}$ & $0.5 \mathrm{~Gy}$ & $24.9 \mathrm{~Gy}$ & 0.7 Gy \\
\hline$D_{5 \mathrm{~cm}^{3}}$ & 0.7 Gy & $0.3 \mathrm{~Gy}$ & $0.3 \mathrm{~Gy}$ & $1.2 \mathrm{~Gy}$ & $0.3 \mathrm{~Gy}$ \\
\hline$D_{\text {mean }}$ & $1.5 \mathrm{~Gy}$ & $1.2 \mathrm{~Gy}$ & $0.3 \mathrm{~Gy}$ & $8.8 \mathrm{~Gy}$ & 0.4 Gy \\
\hline \multicolumn{6}{|l|}{ Chiasm } \\
\hline$D_{2 \%}$ & $2.6 \mathrm{~Gy}$ & $1.9 \mathrm{~Gy}$ & $55.0 \mathrm{~Gy}$ & 0.5 Gy & $19.2 \mathrm{~Gy}$ \\
\hline$D_{0.1 \mathrm{~cm}^{3}}$ & $1.1 \mathrm{~Gy}$ & 0.9 Gy & $21.3 \mathrm{~Gy}$ & $0.3 \mathrm{~Gy}$ & $15.1 \mathrm{~Gy}$ \\
\hline$D_{\text {mean }}$ & $0.9 \mathrm{~Gy}$ & 0.5 Gy & $17.3 \mathrm{~Gy}$ & $0.2 \mathrm{~Gy}$ & 7.5 Gy \\
\hline
\end{tabular}

$D V H$ dose-volume histogram, $P T V$ planning target volume, $G T V$ gross tumor volume, $D v$ absorbed dose in fraction $V_{\%}$ (or $V \mathrm{~cm}^{3}$ ) of the volume in the organ, $V_{D}$ volume receiving at least an absorbed dose $D \%$ (or $D$ Gy), $D_{\text {mean }}$ mean absorbed dose

in $95 \%$ of the PTV was 47.9 Gy (range 45.1-58.9 Gy), and median $D_{98 \%}$, i.e., near-minimum dose of GTV was $51.7 \mathrm{~Gy}$ (range 46.7-60.7 Gy). The median $D_{2 \%}$, i.e., near-maximum dose of the optic nerve and retina was $55.0 \mathrm{~Gy}$ (range 47.8-63.2 Gy) and 8.0 Gy (range 0.9-47.2 Gy), respectively.

Patient \#2 received a prescription dose of 54 Gy (Fig. 1; Table 2). An early improvement of VA and VFs was observed during the treatment course of 4 weeks (Fig. 2; Table 3). $D_{95 \%}$ of the PTV, $D_{98 \%}$ of the GTV, and $D_{2 \%}$ of the optic nerve were 50.3,54.5, and 56.0 Gy, respectively. However, $D_{2 \%}$ and $D_{0.1 \mathrm{~cm}}{ }^{3}$ of the retina in the involved eye were 8.0 and $6.9 \mathrm{~Gy}$, respectively (Table 4), which remained within the acceptable dose range to avoid radiation retinopathy. The patient survives without any evidence of disease and has good visual function, i.e., $\log \mathrm{MAR}=-0.08 /-0.08$ $(\mathrm{VA}=1.2 / 1.2)$ and median depression (MD) of HAP $=$ $-0.55 /-0.32$ (Fig. 2).
In contrast, in patient \#4, the final dose reduced to $46 \mathrm{~Gy}$ from the initial planning dose of $50 \mathrm{~Gy}$ because of his intercurrent diabetes mellitus (Fig. 3; Table 2). Early improvement in his vision was also observed during the treatment course of 2 weeks (Table 3 ). $D_{2 \%}$ and $D_{0.1 \mathrm{~cm}^{3}}$ of the retina in the involved eye were 47.2 and $46.0 \mathrm{~Gy}$, respectively, because of the location of his tumor on the proximal portion of the optic nerve (Fig. 3; Table 4). Despite the acceptable dose levels proposed with QUANTEC (The Quantitative Analysis of Normal Tissue Effects in the Clinic) [7], the patient developed retinal bleeding from the radiation retinopathy 16 months after IMRT (Fig. 4). The combined effect of the posterior retina dose and his intercurrent diabetes mellitus may have caused his retinal bleeding. 


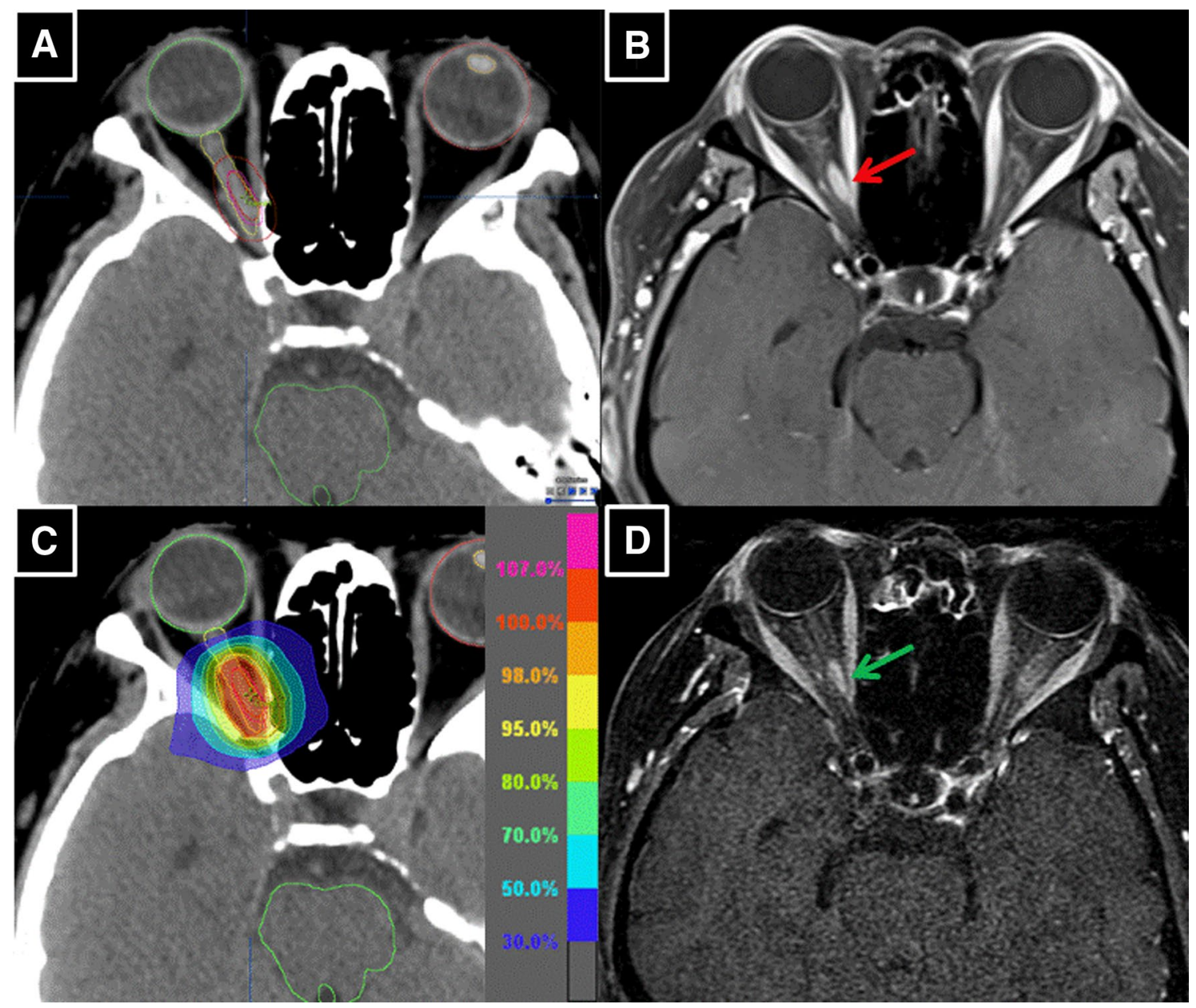

Fig. 1 Patient \#2 was a 57-year-old woman. Pretreatment computed tomography (CT) (a) and magnetic resonance imaging (MRI) showed a 13-mm-long, fusiform type of intraorbital tumor (red arrow) on the medial side of right optic nerve (b). She underwent IMRT of $54 \mathrm{~Gy}$

\section{Discussion}

Because of the extremely rare incidence of this disease, it is sometimes difficult to diagnose as primary ONSM. ONSMs comprise $2 \%$ of all orbital tumors and $1-2 \%$ of all meningiomas [8]. Furthermore, primary ONSM represents only $10 \%$ of all ONSM, all other (90\%) being the secondary ONSM. In our previous report [3], patient \#5 was initially diagnosed as Leber hereditary optic atrophy by the first ophthalmologist, because of the progressive visual loss with central scotoma. An ophthalmologist (O.M.) diagnosed this condition as intraocular lesion, which resulted in the compression of left optic nerve $(\mathrm{ON})$ because of the absence of the family history and the presence of decreased light reflex. MRI showed a globular tumor on the left distal ON at precanalicular portion. Patient was consequently diagnosed with primary ONSM. Many kinds of tumors such as glioma, neurofibroma, schwannoma, fibrous histiocytoma, cavernous in 30 fractions over 43 days in January 2014 (c). MRI performed 46 months after IMRT revealed 39\% reduction of the tumor volume (green arrow) (d)

hemangioma and so on are the mimicking ONSM. Due to the considerable morbidities associated with biopsy, diagnosis of ONS tumors falls heavily on imaging findings, in addition to the clinical presentation. Unenhanced CT may demonstrate diffuse calcification within or along an ONS complex mass, which are highly suggestive of an ONSM. Gadolinium-based contrast enhanced fat-suppression T1W pulse sequences have made a significant contribution to the orbital imaging and gold standard for evaluation of the optic nerve disorders [9].

In this study, early improvement of VA and VFs was observed during the treatment courses among all 5 patients. However, many investigators have already recognized this phenomenon in other countries [1, 10-12]. Most studies have reported that the underlying mechanism was not clear; however, we suggest that the early decompression of the optic nerve sheath, which resulted from the small reduction in the tumor size in the early stage of FSRT, was one of the 


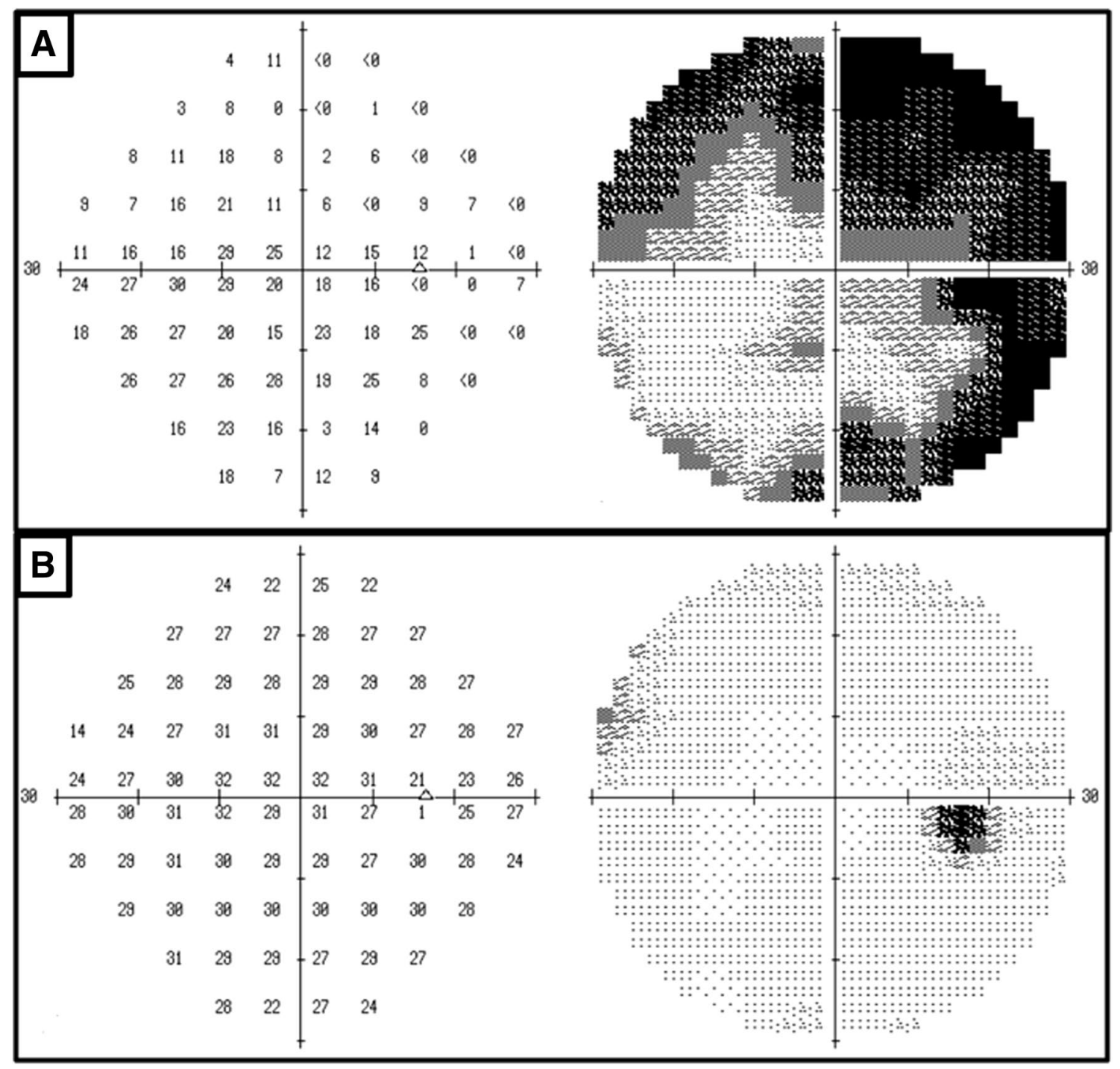

Fig. 2 Patient \#2 had quadrantanopsia before treatment initiation on December 26, 2013. Humphrey automated perimetry (HAP) showed $\mathrm{MD}=-16.18$ (a). During the course of 4 weeks, HAP showed near-

main mechanisms. Jeremić et al. also supposed that the main reason for this observation might actually be a combination of a radiation-induced edema decrease and decompression of the functional nerve structures [1].

In the above FSRT studies, it was generally agreed that functional improvements were not followed by a significant decrease in the tumor size on imaging. Accordingly, Maclean et al. concluded that thorough ophthalmologic assessment was important because clinical responses often occurred in the absence of radiological change, based on their experience of meningiomas (including 3 ONSM) causing visual deficits [13]. Moreover, an improvement in visual function could occur even during the course of FSRT, as well as later in the follow-up period. However, there were controversial reports as to the extent of the tumor shrinkage complete disappearance of the visual field deficit with $\mathrm{MD}=-1.02$ dB on February 27, 2014 (b)

observed after FSRT among large number of the patients with skull base meningioma [14, 15]. Becker et al. reported their experience of 39 patients with ONSM. All patients responded to the treatment. However, almost all patients experienced stable disease, i.e., no change on CT/MRI, and only 1 experienced a partial response [16]. Other investigators reported the same results in the same period $[12,17]$.

In this series, 1 patient developed retinal bleeding from the radiation retinopathy at 16 months after IMRT, probably because of a combination effect with the posterior retina dose and intercurrent diabetes mellitus. Baumert et al. reported that 1 patient developed radiation retinopathy complicated by a vitreous hemorrhage and cataract 4 years after FSRT [6]. A study by Sitathanee et al. described 12 patients treated with FSRT who received a mean dose of 55.5 Gy 


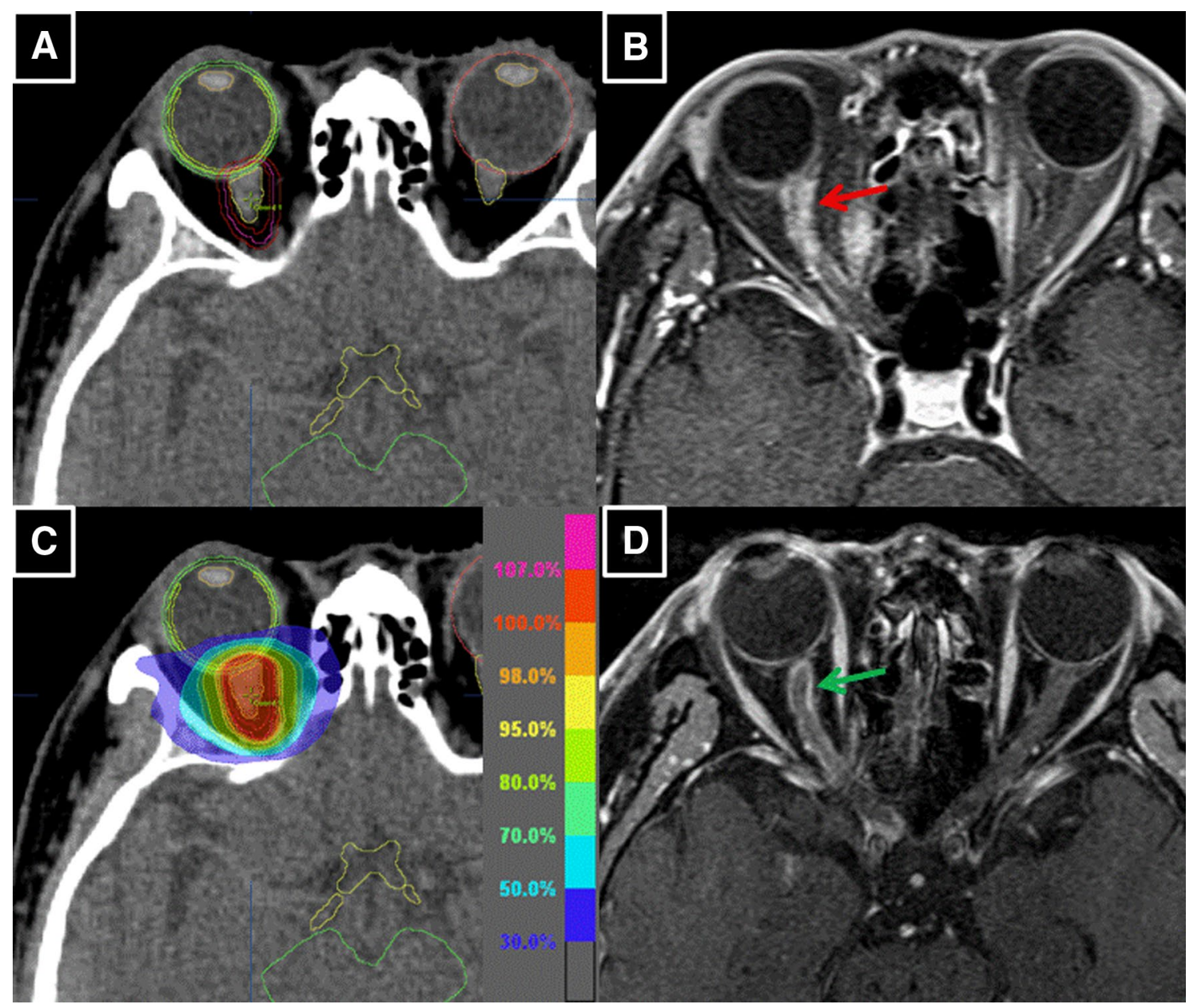

Fig. 3 Patient \#4 was a 61-year-old man. Pretreatment CT (a) and MRI showed a tubular intraorbital tumor (red arrow) of $8 \times 3 \mathrm{~mm}$ located on the proximal portion of the right optic nerve. A "tram-

(range 51.6-59.1 Gy) delivered in 1.8 Gy daily; 1 patient with uncontrolled diabetes and hypertension developed vitreous hemorrhage 2 years after FSRT [17]. A previous case report described a patient with radiation retinopathy occurring 2 years after FSRT (optic nerve dose, 54 Gy in 30 fractions; optic nerve head dose, 48-54 Gy; posterior retina dose, 27.8-48 Gy) without pretreatment factors contributing to its occurrence. Therefore, it remains unclear why this patient developed retinopathy [18].

There is a great discrepancy between the effective IMRT and/or FSRT dose producing early improvement (20-30 Gy) and definitive control of the disease (50 Gy). The lowest controlled dose might be estimated as 30-40 Gy. If a tumor were controlled with a lower dose, it would be better for patients who have a severe intercurrent disease and a high risk of adverse effects, such as radiation retinopathy and/ or optic neuropathy. High-risk patients could refuse definitive radiotherapy for these reasons. However, such high-risk patients cannot undergo radical surgery either. Accordingly, track" sign was also detected (b). He underwent IMRT of 46 Gy in 23 fractions over 31 days in February 2015 (c). MRI taken in August 2015 revealed 53\% reduction of the tumor volume (green arrow) (d)

it is important to investigate safer ways to perform precision IMRT or FSRT for these high-risk patients with severe intercurrent disease.

In this retrospective study, no patients developed radiation-induced optic neuropathy during the follow-up time from 18 to 54 months. Median $D_{2 \%}$ and $D_{0.1 \mathrm{~cm}^{3}}$ for optic nerve was 55.0 Gy (range 47.8-63.2 Gy) and 52.2 Gy (range 40.1-62.5 Gy), respectively.

Many previous studies have investigated radiation tolerance of the optic nerve. Without previous surgical damage to the optic pathways, with a single dose of $<2.0$ Gy and a total dose ranging from 45 to $50 \mathrm{~Gy}$, the risk of radiation optic neuropathy was below $2 \%[19,20]$. When the total dose increased to $54 \mathrm{~Gy}$, the risk of optic neuropathy rose to $5 \%[21,22]$. However, in a study of head and neck cancer with a dose of $<59$ Gy no injury was observed in 106 optic nerves. With a dose of $\geq 60 \mathrm{~Gy}$, the 15 -year actuarial risk of developing optic neuropathy was $47 \%$ with a fraction size of $\geq 1.9 \mathrm{~Gy}$, but this was only $11 \%$ with fractions $<1.9 \mathrm{~Gy}$ 


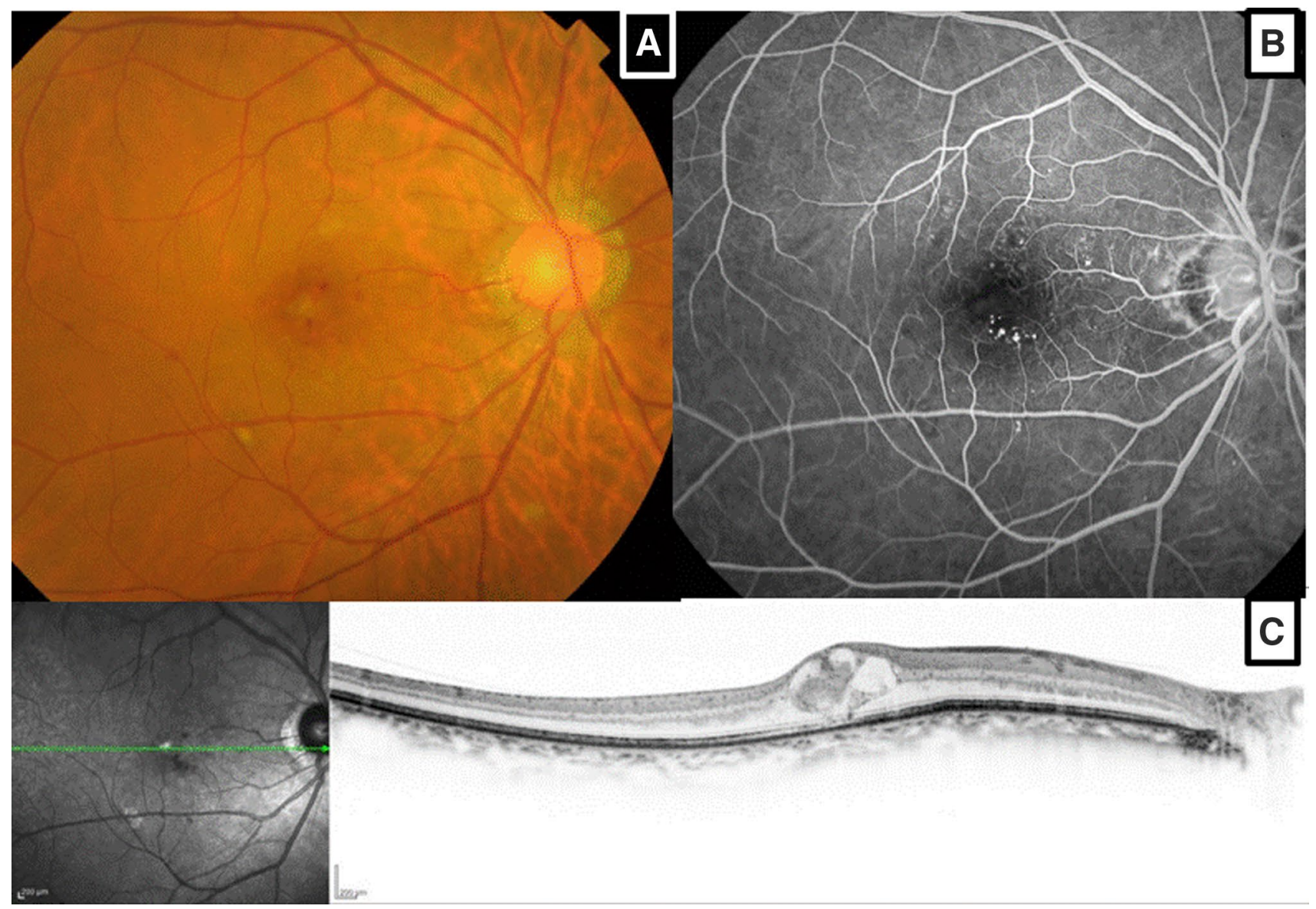

Fig. 4 Patient \#4 with intercurrent diabetes mellitus developed radiation retinopathy. A color fundus photograph showed retinal bleeding at the right macula, which developed 16 months later after completion of IMRT (a). Microaneurysms were observed on the right mac-

[2]. Zenda et al. reported that 4 head and neck tumor patients who received a proton dose from 53.2 GyE (Gy equivalent) to $65.3 \mathrm{GyE}$ developed optic nerve disorders [23]. In a study of carbon therapy, 58\% patients who received irradiation to the optic nerve with $>57 \mathrm{GyE}\left(D_{\max }\right)$ developed radiation optic neuropathy. In addition, a dose of $20 \%$ of the volume of the optic nerve $\left(D_{20}\right)$ was significantly associated with visual loss [24].

Because the conventional tolerance dose proposed for the retina and optic nerve estimated from conventional fractionated radiotherapy does not apply to modern precision radiotherapy $[7,25]$, updated information is necessary to determine the relevant tolerance dose for advanced treatment strategies.

At this moment, there are three primary treatment options for patients with cavernous sinus meningiomas: observation, microsurgical resection, and stereotactic radiosurgery (SRS). SRS may complement surgery or can be only reserved for growing remnants [26]. SRS can be replaced with FSRT or IMRT fundamentally and safely. Advanced radiotherapy ula $30.1 \mathrm{~s}$ after intravenous injection of fluorescent angiography (b). Optical coherence tomography (OCT) showed cystoid macular edema in the horizontal plane (c)

techniques with standard fractionation schedules ( $56 \mathrm{~Gy} / 28$ fractions) can be a good option. The reported local control reached $82-95 \%$ at 5 years and a radiological response rate of $29-31 \%$ was observed. Multisession radiosurgery (mRS) has been evaluated in meningiomas with CyberKnife. When a $25 \mathrm{~Gy}$ in 5 fractions scheme is adopted, the total dose is theoretically comparable to the doses delivered with conventional fractionated regimens (50.4-56 Gy). The indication for mRS was given by the proximity to optic nerve and chiasm or the dimension of the lesion $(>3 \mathrm{~cm})$. The local control rate at 5 years was of $95 \%$. Only $3.5 \%$ of patients experienced a deterioration of preexisting symptoms. Proton has been also advocated to obtain reduced complication in this specific site. High overall 5-year local control rate (96\%) was observed using 57EGy without major toxicity in Loma Linda University [27].

Early intervention with IMRT as well as FSRT resulted in a rapid improvement and reestablishment of visual impairment in 5 patients with ONSM. One patient with diabetes mellitus developed radiation retinopathy 16 months after 
completion of IMRT. The remaining 4 patients have not experienced any late toxicity at the follow-up time from 34 to 54 months. Accordingly, we suggest that early intervention with IMRT as well as FSRT is an effective and standard treatment option for not only stabilizing but also improving the vision of patients with primary ONSM. There has been a substantial shift in the treatment for ONSM from surgery to FSRT in US and EU. While a comprehensive evaluation of radiotherapy is not yet at hand, due to the benign nature of ONSM, limited number of this disease and thus decades of follow-up needed, it seems that this treatment option with early intervention using IMRT and FSRT might in future represent the mainstay of therapy for ONSM in Japan.

Acknowledgements We would like to thank Editage (http://www.edita ge.jp) for English language editing.

\section{Compliance with ethical standards}

Conflict of interest No author has any conflict of interest to disclose.

Open Access This article is distributed under the terms of the Creative Commons Attribution 4.0 International License (http://creativeco mmons.org/licenses/by/4.0/), which permits unrestricted use, distribution, and reproduction in any medium, provided you give appropriate credit to the original author(s) and the source, provide a link to the Creative Commons license, and indicate if changes were made.

\section{References}

1. Jeremić B, Wasik MW, Villà S et al (2008) Stereotactic radiation therapy in primary optic nerve sheath meningioma. In: Jeremić B, Pitz S (eds) Primary optic nerve sheath meningioma. SpringerVerlag, Berlin Heidelberg, pp 105-127

2. Hamilton SN, Nichol A, Truong P et al (2017) Visual outcomes and local control after fractionated stereotactic radiotherapy for optic nerve sheath meningioma. Ophthal Plast Reconstr Surg. https://doi.org/10.1097/IOP.0000000000000914

3. Inoue T, Okuno Y, Nishiguchi I et al (2018) Rapid recovery of vision following early intervention with fractionated stereotactic radiotherapy for optic nerve sheath meningioma. Int Med Case Rep J 11:17-22. https://doi.org/10.2147/IMCRJ.S14952

4. Ortiz O, Schochet SS, Kotzan JM et al (1996) Radiologic-pathologic correlation meningioma of the optic nerve sheath. Am J Neuroradiol 17:901-906

5. Inoue T, Masai M, Oh R-J et al (2014) Adaptive replanning intensity-modulated radiotherapy for choroidal metastasis of breast cancer using optical coherence tomography. J Radiat Res 55(3):502-508

6. Inoue T, Masai $\mathrm{N}$, Shiomi $\mathrm{H}$ et al (2016) Feasibility study of a non-invasive eye fixation and monitoring device using a rightangle prism mirror for intensity-modulated radiotherapy for choroidal melanoma. J Radiat Res 58(3):386-396

7. Marks LB, Yorke ED, Jackson A et al (2010) Use of normal tissue complication probability models in the clinic. Int J Radiat Oncol Biol Phys 76:S10-S19

8. Eddleman CS, Liu JK (2007) Optic nerve sheath meningiomas: current diagnosis and treatment. Neurosurg Focus 23(5):E4
9. Mafee MF, Naheedy JH (2008) Imaging diagnosis of the optic nerve sheath meningioma. In: Jeremić B, Pitz S (eds) Primary optic nerve sheath meningioma. Springer-Verlag, Berlin Heidelberg, pp 39-53

10. Adams G, Roos D, Crompton J (2013) Radiotherapy for optic nerve sheath meningioma: a case for earlier intervention? Clin Oncol 25:356-361

11. Baumert BG, Villà S, Studer G et al (2004) Early improvements in vision after fractionated stereotactic radiotherapy for primary nerve sheath meningioma. Radiother Oncol 72(2):169-174

12. Liu JK, Forman S, Hershewe GL et al (2002) Optic nerve sheath meningiomas: visual improvement after stereotactic radiotherapy. Neurosurgery 50:950-957

13. Maclean J, Fersht N, Brenner F et al (2013) Meningioma causing visual impairment: outcomes and toxicity after intensity modulated radiation therapy. Int J Radiat Oncol Biol Phys 85:e179-e186

14. Henzel M, Gross MW, Hemm K et al (2006) Significant tumor volume reduction of meningiomas after stereotactic radiotherapy: results of a prospective multicenter study. Neurosurgery 59:1188-1194

15. Henzel M, Gross MW, Hemm K et al (2006) Stereotactic radiotherapy of meningiomas. Symptomatology, acute and late toxicity. Strahlenther Onkol 182:382-388

16. Becker G, Jeremić B, Pitz S et al (2002) Stereotactic fractionated radiotherapy in patients with optic nerve sheath meningioma. Int J Radiat Oncol Biol Phys 54:1422-1429

17. Sitathanee C, Dhanachai M, Poonyathalang A et al (2006) Stereotactic radiation therapy for optic nerve sheath meningioma: an experience at Ramathibodi Hospital. J Med Assoc Thai 89:1665-1669

18. Subramanian PS, Brssler NM, Miller NR (2004) Radiation retinopathy after fractionated stereotactic radiotherapy for optic nerve sheath meningioma. Ophthalmology 111:565-567

19. Brada M, Bajan B, Traish D et al (1993) The long-term efficacy of conservative surgery and radiotherapy in the control of pituitary adenomas. Clin Endocrinol (Oxf) 38(6):571-578

20. Becker G, Kocher M, Kortmann RD et al (2002) Radiation therapy in the multimodal treatment approach of pituitary adenoma. Strahlenther Onkol 178:173-186

21. Goldsmith BJ, Rosenthal SA, Wara WM et al (1992) Optic neuropathy after irradiation of meningioma. Radiology 185:71-76

22. Parsons JT, Bova FJ, Fitzgerald CR et al (1994) Radiation optic neuropathy after megavoltage external-beam irradiation: analysis of time-dose factor. Int J Radiat Oncol Biol Phys 30:755-763

23. Zenda S, Kawashima M, Arahira S et al (2015) Late toxicity of proton beam therapy for patients with the nasal cavity, para-nasal sinuses, or involving the skull base malignancy: importance of long-term follow-up. Int J Clin Oncol 20(3):447-454

24. Hasegawa A, Mizoe J, Mizota A et al (2006) Outcomes of visual acuity in carbon ion radiotherapy: analysis of dose-volume histograms and prognostic factors. Int J Radiat Oncol Biol Phys 64:396-401

25. Emami B, Lyman J, Brown A et al (1991) Tolerance of normal tissue to therapeutic irradiation. Int J Radiat Oncol Biol 21:109-122

26. Sindou M, Nebbal M, Guclu B (2015) Cavernous sinus meningiomas: imaging and surgical strategy. Adv Tech Stand Neurosurg 42:103-121. https://doi.org/10.1007/978-3-319-09066-5_6

27. Fariselli L, Biroli A, Signorelli A et al (2016) The cavernous sinus meningiomas' dilemma: surgery or stereotactic radiosurgery? Rep Pract Oncol Radiother 21(4):379-385. https://doi.org/10.1016/j. rpor.2015.05.002 